\title{
Anticancer Medications and Sodium Dysmetabolism
}

\author{
Aishwarya Krishnamurthy, ${ }^{1}$ Saptarshi Bhattacharya, ${ }^{1}$ Tejal Lathia, ${ }^{2}$ Viny Kantroo, ${ }^{3}$ Sanjay Kalra ${ }^{4}$ and Deep Dutta ${ }^{5}$ \\ 1. Endocrinology Department, Max Super Speciality Hospital, Patparganj, New Delhi, Delhi, India; 2. Endocrinology Department, Fortis \\ Hospital, Vashi, Navi Mumbai, Maharashtra, India; 3. Respiratory Department, Critical Care and Sleep Medicine, Apollo Hospitals, Sarita Vihar, \\ New Delhi, Delhi, India; 4. Endocrinology Department, Bharti Hospital, Karnal, Haryana, India; 5. CEDAR Superspeciality Clinics, Dwarka, \\ New Delhi, Delhi, India
}

DOI: https://doi.org/10.17925/EE.2020.16.2.122

$\mathrm{T}$ herapeutic advances have revolutionised cancer treatment over the last two decades, but despite improved survival and outcomes, adverse effects to anticancer therapy such as dyselectrolytaemias do occur and need to be managed appropriately. This review explores essential aspects of sodium homeostasis in cancer with a focus on alterations arising from anticancer medications. Sodium and water balance are tightly regulated by close interplay of stimuli arising from hypothalamic osmoreceptors, arterial and atrial baroreceptors and the renal juxtaglomerular apparatus. This delicate balance can be disrupted by cancer itself, as well as the medications used to treat it. Some of the conventional chemotherapeutics, such as alkylating agents and platinum-based drugs, can cause hyponatraemia and, on rare occasions, hypernatraemia. Other conventional agents such as vinca alkaloids, as well as newer targeted cancer therapies including small molecule inhibitors and monoclonal antibodies, can cause hyponatraemia, usually as a result of inappropriate antidiuretic hormone secretion. Hyponatraemia can also sometimes occur secondarily to drug-induced hypocortisolism or salt-wasting syndromes. Another atypical but distinct mechanism for hyponatraemia is via pituitary dysfunction induced by immune checkpoint inhibitors. Hypernatraemia is uncommon and occasionally ensues as a result of drug-induced nephrogenic diabetes insipidus. Identification of the aetiology and appropriate management of these conditions, in addition to averting treatment-related problems, can be lifesaving in critical situations.

\section{Keywords}

Anticancer medications, hyponatraemia, hypernatraemia, dyselectrolytaemia, syndrome of inappropriate secretion of antidiuretic hormone (SIADH)

Disclosures: Aishwarya Krishnamurthy, Saptarshi Bhattacharya, Tejal Lathia, Viny Kantroo, Sanjay Kalra and Deep Dutta have no financial or non-financial relationships or activities to declare in relation to this article. Sanjay Kalra and Deep Dutta are members of the journal's Editorial Board.

Review Process: Double-blind peer review. Compliance with Ethics: This article involves a review of literature and does not report on new clinical data, or any studies with human or animal subjects performed by any of the authors.

Authorship: All named authors meet the International Committee of Medical Journal Editors (ICMJE) criteria

for authorship of this manuscript, take responsibility

for the integrity of the work as a whole, and have given final approval for the version to be published.

Access: This article is freely accessible at

touchENDOCRINOLOGY.com @Touch Medical Media 2020

Received: 16 April 2020

Accepted: 4 May 2020

Published Online: 1 October 2020

Citation: European Endocrinology. 2020;16(2):122-30

Corresponding Author: Saptarshi Bhattacharya,

Department of Endocrinology, Max Super Speciality

Hospital, 108A IP Extension, Patparganj, Delhi,

India 110092. E: saptarshi515@gmail.com

Support: No funding was received in

the publication of this article.
Recent advances have bolstered the anticancer therapeutic armamentarium. However, despite the enhanced efficacy and better survival offered by these newer agents, side effects remain a source of concern. ${ }^{1}$ Gastrointestinal side effects, organ toxicities and dyselectrolytaemias are critical adverse consequences. Among these, dyselectrolytaemias are multifactorial and need to be monitored and managed appropriately. ${ }^{1}$ In this review, we aim to describe the pathophysiology and abnormalities of sodium homeostasis occurring as a consequence of anticancer medications.

\section{Literature search strategy}

The medical literature for this review was identified through PubMed searches for articles published from inception to March 2020, by use of the terms 'hyponatraemia', 'hypernatraemia', 'sodium abnormalities', 'sodium homeostasis', 'dyselectrolytaemia' in combination with 'antineoplastic agent', 'anticancer agent', 'cancer chemotherapy'; 'vinca alkaloids' including 'vincristine', 'vinblastine', 'vinflunine'; 'platinum containing compounds' including 'cisplatin', 'carboplatin', 'oxaliplatin'; 'alkylating agents' including 'chlorambucil', 'cyclophosphamide', 'ifosfamide', 'busulphan', 'melphalan'; 'immune checkpoint inhibitor' including 'ipilimumab', 'nivolumab', 'pembrolizumab', 'atezolizumab', 'avelumab', 'durmalumab'; 'monoclonal antibodies' including 'cetuximab', 'panitumumab', 'alemtuzumab', 'trastuzumab', 'ado-trastuzamab emtansine', 'rituximab', 'crelizumab', 'obinutuzumab', 'veltuzumab', 'ofatumumab', 'bevacizumab'; 'immunomodulators for cancer' including 'cytokines', 'interferon- $\alpha$,' 'interleukin-2', 'thalidomide analogues', 'thalidomide', 'Ienalidomide', 'pomalidomide', 'chimeric antigen receptor T cell therapy', 'axicabtagene ciloleucel', 'tisagenlecleucel'; 'tyrosine kinase inhibitors' including 'imatinib', 'dasatinib', 'nilotinib', 'bosutinib', 'axitinib', 'sorafenib', 'brivanib', 'gefitinib', 'erlotinib', 'afatinib'; 'mammalian target of rapamycin inhibitors' including 'temsirolimus', 'everolimus'; 'proteasome inhibitors' including 'bortezomib', 'carfilzomib', 'ixazomib'; 'histone deacetylase inhibitor' including 'vorinostat', 'romidepsin', 'belinostat'; 'hormonal therapy for cancer' including 'goserelin', 'leuprorelin', 'leuprolide', 'triptorelin'; 'ancillary therapy for cancer', 'opioids' including 'codeine', 'morphine', 'apomorphine', 'hydrocodone'; 'non-steroidal anti-inflammatory drugs' including 'ibuprofen', 'indomethacin'; 'tricyclic antidepressants' including 'amitryptiline'; 'anticonvulsants', including 'pregabalin', 'gabapentin', 'carbamazepine'; 'hypouricosuric agents' including 'allopurinol', 'febuxostat', 'rasburicase'; 'proton pump inhibitors', including 'omeprazole', 'esomeprazole', 'pantoprazole'; 'osteoporosis therapy' including 'zoledronic acid'. Relevant articles were also identified through Google Scholar searches. Articles identified from these searches and related references cited in those articles were reviewed. Only articles published in English language were included. 


\section{Physiology of sodium homeostasis}

Sodium homeostasis is closely linked to plasma osmolality. Usually, plasma osmolality is maintained between 275-290 mosmol/kg and serum sodium between 135-145 mmol/L, with variations depending on the assays used. Sodium balance is intricately regulated by the concerted action of different neurohumoral systems. ${ }^{2-5}$

\section{Change in plasma osmolality}

Hypothalamic osmoreceptors function as the primary defence against a rising plasma osmolality and stimulate thirst by activating neurons projecting to the hypothalamic supraoptic and paraventricular nuclei. ${ }^{6}$ On the other hand, a decrease in plasma osmolality is countered by suppression of antidiuretic hormone (ADH) or arginine vasopressin (AVP) secretion. ${ }^{7}$ AVP is usually secreted above a plasma osmolality threshold of 280-290 mOsmol/kg and acts on V2 vasopressin receptors (V2R) located in the renal collecting tubule and distal convoluted tubule to increase permeability and reabsorption of water. ${ }^{8,9}$

\section{Effective arterial volume}

The homeostatic mechanisms that maintain effective arterial volume also play an important role in sodium homeostasis. The changes in effective arterial volume are sensed by the arterial baroreceptors (carotid sinus and aortic arch), the atrial volume receptors and the juxtaglomerular apparatus in the kidney. ${ }^{10-12} \mathrm{~A}$ fall in blood pressure enhances the sympathetic activity to enhance cardiac output and induce vasoconstriction, and vice versa. ${ }^{13}$ In response to volume or pressure overload, atrial receptors control the release of atrial natriuretic peptide from the atria and brain natriuretic peptide from the ventricles. Both these peptides have diuretic, natriuretic and vasodilatory properties. ${ }^{14}$ Hypotension induced by a substantial reduction in effective arterial volume can stimulate the non-osmotic release of AVP.15

\section{Renal blood flow and sodium delivery}

The juxtaglomerular apparatus secretes renin in response to a reduction in renal blood flow or a decrease in sodium delivery to the distal convoluted tubule, and activates the renin-angiotensin-aldosterone system (RAAS). Unlike baroreceptor mediated acute changes, activation of the RAAS causes sodium and water retention with resultant elevation in arterial tone and blood pressure, in a more sustained manner.16

\section{Sodium homeostasis in patients with cancer}

Sodium imbalance is common in patients who have cancer. ${ }^{17-20}$ Hyponatraemia is more commonly observed in comparison with hypernatraemia. ${ }^{20}$ The derangements can be categorised as follows.

\section{Hyponatraemia}

Hyponatraemia has a heterogenous aetiology including iatrogenic causes, and occurs with an incidence that ranges between 4-44\%.17,21 syndrome of inappropriate secretion of $A D H$ (SIADH) is the most common cause and can occur as a paraneoplastic manifestation, as a response to central nervous system (CNS) lesions (intracranial tumours, meningitis, cranial irradiation, primary or metastatic lesions), pulmonary disease (pneumonia, tuberculosis, metastasis) or as an adverse effect of cancer therapy. ${ }^{19,22-24}$ Conversely, certain drugs like cyclophosphamide (CYC), nonsteroidal anti-inflammatory drugs and antiepileptic drugs (e.g., carbamazepine) can increase renal ADH sensitivity, causing a nephrogenic syndrome of inappropriate antidiuresis (NSIAD). ${ }^{25}$

Apart from SIADH, usual causes of hypovolaemic (e.g., due to renal or extra-renal fluid losses) and hypervolaemic (e.g., heart failure, cirrhosis) hyponatraemia can also occur in individuals with cancer. ${ }^{26}$ Renal salt-wasting syndrome (RSWS) can occur due to cytotoxic therapy, adrenal insufficiency or very rarely from paraneoplastic atrial natriuretic peptide or brain natriuretic peptide secretion. ${ }^{26-28}$ Glucocorticoid deficiency, hypothyroidism, or both, can result from hypopituitarism due to tumours affecting the sellar region and can cause hyponatraemia. ${ }^{29}$ Surgical therapies such as ileal or jejunal duct choleresis after biliary drainage, and prostatic or uterine irrigation during interventions, can also cause hyponatraemia. Cerebral salt-wasting syndrome (CSWS), a close differential diagnosis of SIADH, can occur after surgery for pituitary tumours, acoustic neuromas or gliomas, and is accompanied by hypovolaemia, a feature that is not associated with SIADH. ${ }^{30}$ Thus, hyponatraemia can occur as a consequence of cancer or its complications, and as a result of anticancer or ancillary therapy. Quantifying the contribution of specific chemotherapeutic agents in the pathogenesis of hyponatraemia remains a challenge.

\section{Pseudohyponatraemia}

Falsely low sodium measurements can occur in individuals with multiple myeloma, Waldenström's macroglobulinaemia and malignant lymphoproliferative disorders (due to hyperglobulinaemia), as well as in those with severe hypertriglyceridaemia or hyperglycaemia. ${ }^{31,32}$ These abnormalities need to be considered when interpreting reports for certain patients with cancer.

\section{Hypernatraemia}

Hypernatraemia occurs less often than hyponatraemia and has multifactorial aetiologies (including fluid restriction, diuretic therapy, glucocorticoid administration and renal concentrating defects) due to tubular damage induced by drugs such as platinum compounds, ifosfamide, amphotericin, cidofovir and foscarnet. Furthermore, diarrhoea, vomiting and insensible losses from perspiration that occur in neutropenic fevers can contribute to hypovolaemic hypernatraemia. Rarely, diabetes insipidus can cause hypernatraemia, but only when fluid intake is restricted. ${ }^{20}$

\section{Overview of anticancer drugs}

The advent of 'personalised medicine' has revolutionised anticancer strategies over the last two decades. While time-tested conventional systemic chemotherapy is still widely in use, there is a growing interest in the development of newer agents that 'target' specific processes or proteins in cancer cells that differentiate them from normal healthy cells. Targeted therapy is different from conventional chemotherapeutic agents, which indiscriminately affect all cells (healthy and cancerous), causing more adverse effects. ${ }^{33}$ Conventional agents include antimetabolites, alkylating agents, antimicrotubular agents, antitumour antibiotics and topoisomerase inhibitors, amongst others. Targeted therapy encompasses monoclonal antibodies (mAbs), including immune checkpoint inhibitors, some immunomodulators, hormonal agents and small molecule inhibitors. Small molecule inhibitors comprise tyrosine kinase inhibitors (TKIS), mammalian target of rapamycin (mTOR) inhibitors, proteasome inhibitors, matrix metalloproteinases and heat shock inhibitors, and several other investigational agents. ${ }^{34}$ Tables 1 and 2 summarise the effect of conventional anticancer agents and targeted therapies on sodium homeostasis, respectively.

\section{Vinca alkaloids}

Among vinca alkaloids, vincristine and, less commonly, vinblastine can cause hyponatraemia. ${ }^{35-37}$ The incidence of vincristine-related suspected or proven SIADH in a paediatric series of patients with acute lymphoblastic leukaemia varied between 5.9\% (5/84) in a Polish series, 
Table 1: Mechanism of sodium abnormalities caused by conventional cytotoxic agents and probable underlying causal mechanisms

\begin{tabular}{|c|c|c|c|c|}
\hline Anticancer agent & Sodium abnormality & Time to onset & Mechanism & Comments \\
\hline Vincristine & Hyponatraemia & $1-2$ weeks & $\begin{array}{l}\text { - SIADH - direct toxicity to neurohypophysis and } \\
\text { hypothalamus causing abnormal osmoreceptor } \\
\text { control of ADH secretion }{ }^{46-48}\end{array}$ & $\begin{array}{l}\text { Antifungal azoles can inhibit metabolism and } \\
\text { worsen hyponatraemia/neurotoxicity }{ }^{44}\end{array}$ \\
\hline \multirow[t]{2}{*}{$\begin{array}{l}\text { Platinum } \\
\text { compounds }\end{array}$} & Hyponatraemia & $1-2$ days & $\begin{array}{l}\text { - } \text { SIADH - unclear mechanism }{ }^{65-68} \\
\text { RSW - cisplatin-induced renal } \\
\text { - } \text { Potentar necrosis stimulation of ADH by } \\
\text { therapy-induced nausea } \\
\text { - } \text { Overzealous administration of large volumes of } \\
\text { hypotonic fluid } 51,69\end{array}$ & $\begin{array}{l}\text { Overzealous co-administration of hypotonic fluid } \\
\text { to be avoided }\end{array}$ \\
\hline & Hypernatraemia & - & $\begin{array}{l}\text { - } \text { Acquired NDI - reduced expression of } \\
\text { AQP2 channels on apical membranes of } \\
\text { renal tubules }{ }^{45,52,70} \\
\text { - } \text { Cisplatin-induced hypokalaemia can cause } \\
\text { reversible NDI by decreasing AQP2 expression; } \\
\text { hypokalaemia-induced polydipsia and } \\
\text { resulting polyuria } 71,72\end{array}$ & Avoid dehydration, encourage liberal fluid intake \\
\hline \multirow[t]{2}{*}{ Alkylating agents } & Hyponatraemia & $\begin{array}{l}\text { Usually } \\
4-12 \text { hours } \\
\text { (sometimes up } \\
\text { to } 48 \text { hours) }\end{array}$ & $\begin{array}{l}\text { - } \text { SIADH }{ }^{80,82,84} \\
\text { NSIAD - V2R activation and AQP2 induction } \\
\text { via downregulation of inhibitory inflammatory } \\
\text { mediators like IL-1 and TNF } \alpha^{85-88,90}\end{array}$ & $\begin{array}{l}\text { Overzealous use of hypotonic fluids to prevent } \\
\text { haemorrhagic cystitis during cyclophosphamide } \\
\text { infusion can worsen hyponatraemia }\end{array}$ \\
\hline & Hypernatraemia & - & - Acquired ND|45,52,91,92 & Avoid dehydration, encourage liberal fluid intake \\
\hline
\end{tabular}

ADH = antidiuretic hormone; $A Q P 2$ = aquaporin-2; IL-1 = interleukin-1; NDI = nephrogenic diabetes insipidus; NSIAD = nephrogenic syndrome of inappropriate antidiuresis; RSWS = renal salt-wasting syndrome; SIADH = syndrome of inappropriate secretion of antidiuretic hormone; TNF $\alpha=$ tumour necrosis factor- $\alpha$; V2R = vasopressin receptor type 2.

Table 2: Targeted anticancer therapies causing hyponatraemia and their probable underlying causal mechanisms

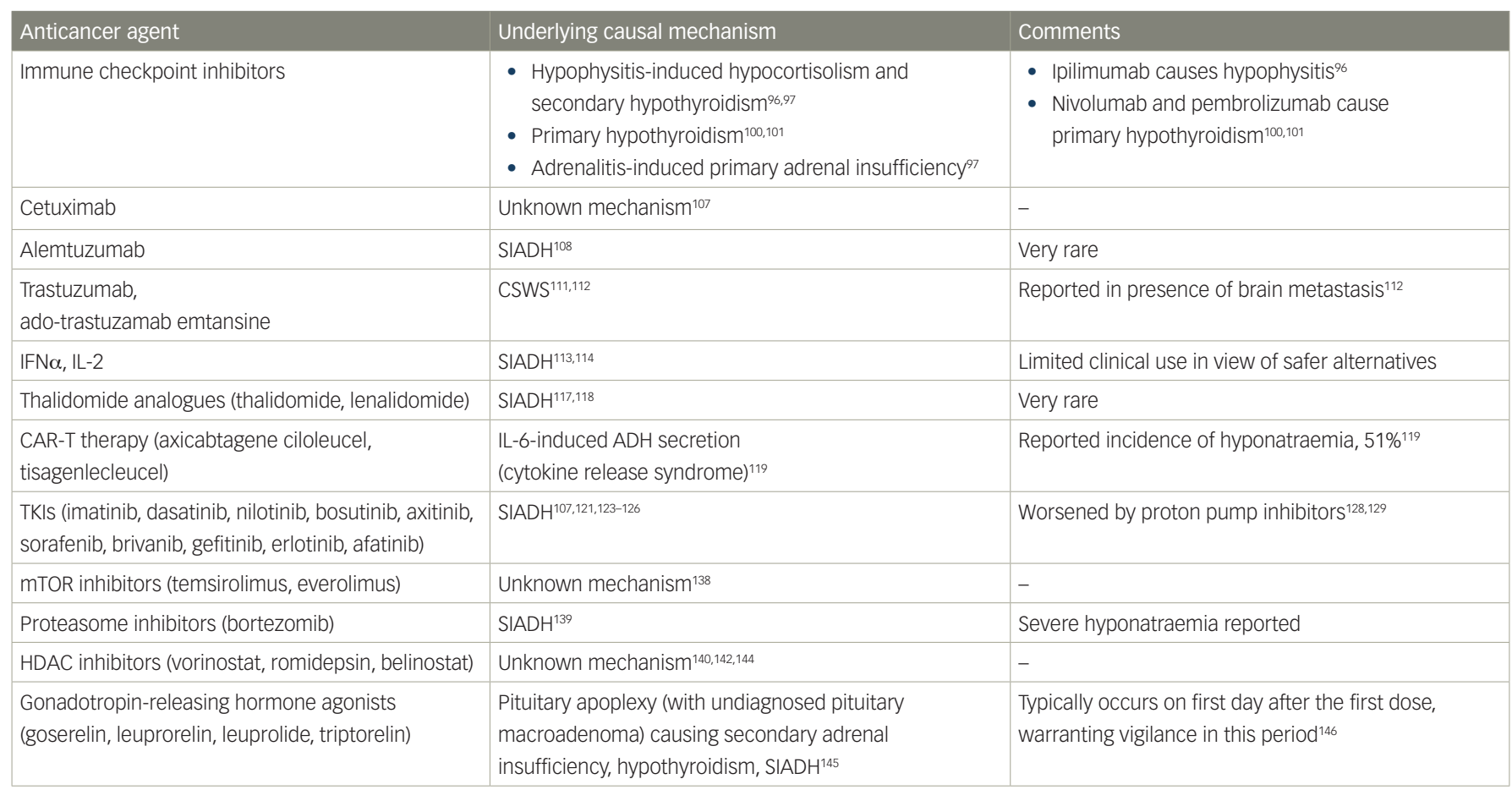

$A D H=$ antidiuretic hormone; $C A R-T=$ chimeric antigen receptor $T$ cell; $C S W S=$ cerebral salt-wasting syndrome; HDAC = histone deacetylase; IFN $\alpha=$ interferon $\alpha ;$ IL-2 = interleukin-2; $\mathrm{LL}-6=$ interleukin-6; $m T O R=$ mammalian target of rapamycin; SIADH = syndrome of inappropriate secretion of antidiuretic hormone; TKI = tyrosine kinase inhibitor.

$11.2 \%(68 / 605)$ in a study from the USA and $10.8 \%(18 / 166)$ in a report from India. ${ }^{38-40} \mathrm{~A}$ history of hyponatraemia correlated with the occurrence of neurologic complications and was found to be a marker of overt CNS leukaemia. ${ }^{38}$ The newer agent, vinflunine, can also cause hyponatraemia, with an incidence of approximately $12 \%(6 / 51) .{ }^{41}$ Severe hyponatraemia (defined as serum sodium $<130 \mathrm{mmol} / \mathrm{L}$ in the study) was found in $11.9 \%$ (10/84) of children on chemotherapy for acute lymphoblastic leukaemia and occurred shortly after administration of vincristine. ${ }^{38}$ Acute life-threatening hyponatraemia with seizure and coma has also been reported with vincristine..$^{42}$ In a retrospective analysis, Asians were found 
to be over-represented among patients developing vincristine-induced hyponatraemia, though the possible reason behind this observation is not apparent. ${ }^{43}$

Given with antifungal azoles (itraconazole, posaconazole, voriconazole and ketoconazole), the incidence of SIADH with vincristine is as high as 44\% (21/47). Antifungal agents inhibit vincristine metabolism, which can lead to an increase in drug levels and subsequent neurotoxicity. ${ }^{44}$

Hyponatraemia commonly occurs after a delay of 1-2 weeks following administration of vincristine and lasts for about 2 weeks. It is often preceded by neurological manifestations that are not directly related to hyponatraemia, such as paralytic ileus or paresthaesia. ${ }^{45}$ Doses of vincristine ranging from $1.2-2.0 \mathrm{mg} / \mathrm{m}^{2}$ have been reported to result in hyponatraemia. ${ }^{35}$ In two patients, one with metastatic malignant melanoma and the other with a primitive neuroendocrine tumour, a lower risk of hyponatraemia was observed when vinblastine $(0.4 \mathrm{mg} / \mathrm{kg})$ was given on days 1 and 4 , instead of consecutively on the first 2 days of the regimen. ${ }^{37}$

\section{Underlying causal mechanism}

SIADH is usually responsible for the development of hyponatraemia and presumably occurs as a result of the direct toxic effect on the neurohypophysis and hypothalamus, leading to abnormalities in the osmoreceptor control of ADH secretion. The presence of abnormally elevated serum and urine ADH levels that has been observed concomitantly with clinical hyponatraemia in several patients corroborates this hypothesis. ${ }^{46-48}$ Further, the neurotoxic effects of vincristine have been histopathologically demonstrated in animal models (chicks and rats), as well as in human studies. ${ }^{49-51}$ The autopsy report of a patient who had received vincristine showed the presence of axonal spheroids in the ansa lenticularis and the area surrounded by the substantia innominata, amygdala and supraoptic nucleus. It was proposed that these spheroids interfered with the inhibitor function of the supraoptic nucleus. Peripheral neuropathy is also presumed to occur from direct neurotoxicity of vincristine. ${ }^{51}$

Occurrence of hypernatraemia has not been attributed to vinca alkaloids Vinblastine can cause nephrogenic diabetes insipidus (NDI); however, hypernatraemia has not been reported in connection to NDI. ${ }^{52}$

\section{Platinum-containing compounds}

Platinum-containing anticancer drugs include cisplatin, carboplatin and oxaliplatin. They can cause multiple dyselectrolytaemias, affecting magnesium, potassium, calcium and sodium balance. ${ }^{53}$ Hyponatraemia and, rarely, hypernatraemia are the commonly reported sodium abnormalities.

\section{Hyponatraemia}

The incidence of hyponatraemia after intravenous administration of cisplatin was $67.2 \%$ (317/472) in a retrospective evaluation over 5 years in a middle-aged population with mixed cancer types. In that report, hyponatraemia was mild in $56.6 \%$ (267/472) of recipients (categorised as 130-137 mmol/L in the study); 8.9\% (42/472) had serum sodium between 120-129 mmol/L; and only 1.7\% (8/472) had sodium levels below $120 \mathrm{mmol} / \mathrm{L}$. The median time for progression of serum sodium levels to below $129 \mathrm{mmol} / \mathrm{L}$ was 7 days. ${ }^{54}$

A significant rise in urinary $\mathrm{N}$-acetyl- $\beta$-glucosaminidase levels within the first 2 days after cisplatin infusion is reported to be a predictor of cisplatin-associated severe hyponatraemia. ${ }^{55}$ Other important risk factors for hyponatraemia induced by cisplatin are old age ( $>65$ years), presence of small cell lung cancer or oesophageal cancer and low sodium levels (<138 mmol/L) at the onset of therapy..$^{54}$ Carboplatin, oxaliplatin (used for advanced gastric cancer) and nedaplatin (used for untreated advanced or relapsed squamous cell lung carcinoma) have a lower incidence of hyponatraemia as compared with cisplatin. ${ }^{35,56-58}$

\section{Underlying causal mechanism}

There is evidence supporting the contribution of RSWS as well as SIADH in the pathogenesis of hyponatraemia. ${ }^{58-60}$

\section{Renal salt-wasting syndrome}

Cisplatin-induced tubular necrosis causes magnesium, potassium and calcium loss, and possibly renal sodium loss causing hyponatraemia, corroborating the possible role of RSWS.61,62 A direct relationship between the dose and occurrence of RSWS has not been clearly defined in the literature. It can happen a few days to several months after medication exposure, suggestive of a cumulative renal effect. Recovery can occur in days to months, or it may persist. 63,64

Syndrome of inappropriate secretion of antidiuretic hormone Literature suggests that SIADH could also play a part in the development of hyponatraemia in some cases. The clinical characteristics and temporal profile are distinct from that of RSWS. Onset is early, occurring in the first 2 days after administration of cisplatin, and sodium levels normalise rapidly after removal of the offending drug. ${ }^{65-68}$

\section{Other causes}

Additional underlying mechanisms that may contribute to hyponatraemia include stimulation of $\mathrm{ADH}$ by therapy-induced nausea and overzealous co-administration of large volumes of hypotonic fluid to prevent nephrotoxicity. ${ }^{35,51,69}$

\section{Hypernatraemia}

Both cisplatin and carboplatin can cause acquired NDI and hypernatraemia, resulting from reduced expression or impaired delivery of aquaporin-2 (AQP2) channels to the apical membrane of renal tubules.45,52,70 Hypokalaemia from cisplatin can also lead to the development of reversible NDI by decreasing the expression of AQP2 in the distal convoluted tubule. ${ }^{71}$ Recovery occurs within 1-12 weeks after the correction of serum potassium levels. In addition to NDI, direct stimulation of thirst and increased water consumption by low potassium levels also contributes to polyuria., ${ }^{17,72}$

\section{Alkylating agents}

Alkylating agents like chlorambucil, CYC and ifosfamide can cause hyponatraemia or rarely hypernatraemia. ${ }^{45}$

\section{Hyponatraemia}

CYC-induced hyponatraemia usually occurs 4-12 hours (sometimes up to 48 hours) after intravenous administration and reverses within 24 hours. It can be severe and result in seizures, lethargy or altered behaviour. ${ }^{73-75}$ It is commonly observed with high doses of CYC (30-50 mg/kg); however, it has also been reported following lower doses of 10-15 mg/kg and even after a single dose of $500 \mathrm{mg} .{ }^{73-79}$ In a cohort of 69 patients receiving high-dose CYC, the reported cumulative incidence of hyponatraemia ( $<135 \mathrm{mmol} / \mathrm{L}$ ) was $52 \%$ (36), with severe hyponatraemia (defined as $<120 \mathrm{mmol} / \mathrm{L}$ in the study) occurring in 5.8\% (4), and symptomatic hyponatraemia in $8.7 \%(6){ }^{78}$ It has also been observed with other alkylating agents: busulfan, melphalan, glufosfamide and ifosfamide. ${ }^{80-82}$ 
Overzealous use of intravenous hypotonic fluids to prevent haemorrhagic cystitis during CYC infusion can aggravate hyponatraemia. An alternative approach would be to use isotonic fluids with close monitoring of sodium levels. ${ }^{74,75}$ Hyponatraemia that occurs during therapy might require discontinuation of the alkylating agent and/or fluid restriction. Use of intravenous conivaptan therapy permitted the continuation of ifosfamide along with standard hydration protocols in a patient with diffuse large B-cell lymphoma. ${ }^{83}$

\section{Underlying causal mechanism}

SIADH is the dominant mechanism behind hyponatraemia and can be due to either central release of $\mathrm{ADH}$ or potentiation of the renal tubular effects of ADH (NSIAD). ${ }^{77,83}$

\section{Central syndrome of inappropriate secretion of antidiuretic hormone}

The alkylating agents busulfan, melphalan, glufosfamide and ifosfamide cause hyponatraemia by increasing hypothalamic production of $\mathrm{ADH} .80,82,84$

\section{Nephrogenic syndrome of inappropriate antidiuresis}

CYC causes diuresis and natriuresis in rabbits without an increase in AVP. It can activate V2R and induce AQP2 upregulation in the absence of AVP in the rat kidney. ${ }^{85}$ Intravenous CYC infusion in a patient with established central diabetes insipidus and no ability for AVP synthesis resulted in a temporary decrease in urine output with an increase in urine specific gravity, indicating a direct tubular effect of $\mathrm{CYC}$ or its metabolites. ${ }^{86}$ Increased interleukin-1 (IL-1) and nuclear factor-кB, a transcriptional factor of tumour necrosis factor- $\alpha$ (TNF $\alpha$ ), have been shown to reduce expression of $\mathrm{V} 2 \mathrm{R}$ and $\mathrm{AQP} 2$ in renal tubules. ${ }^{87,88}$ CYC-mediated suppression of these inflammatory mediators upregulate $\mathrm{V} 2 \mathrm{R}$ and $\mathrm{AQP} 2$ expression in the renal tubules and has been hypothesised to induce NSIAD. ${ }^{99}$ CYC metabolites implicated in reducing the synthesis of IL-1 and TNF $\alpha$ in a dose-dependent fashion are mafosfamide and 4-hydroperoxycyclophosphamide. ${ }^{90}$ These observations provide a plausible mechanism of CYC-mediated NSIAD.

\section{Hypernatraemia}

Ifosfamide produces significant renal damage, particularly involving the proximal tubules and can lead to Fanconi's syndrome. It can also cause distal tubular damage, resulting in type 1 renal tubular acidosis and NDI.55,51 CYC and bendamustine have also been associated with

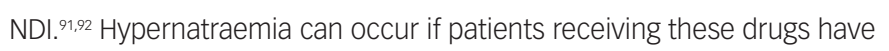
restricted fluid intake or develop dehydration from other causes, and has been reported with bendamustine..$^{92}$ Hypernatraemia has not been reported as yet with $\mathrm{CYC}$ or ifosfamide.

\section{Immune checkpoint inhibitors}

Immune checkpoint molecules, namely cytotoxic T-lymphocyteassociated protein 4 (CTLA4) and programmed cell death protein-1 (PD-1, a cell surface receptor) and its ligand (PD-L1), prevent the immune system from destroying its cells. Immune checkpoint inhibitors are mAbs directed against CTLA4, PD-1 or PD-L1. Cancer cells usually overexpress immune checkpoint molecules to evade immune destruction and immune checkpoint inhibitors act by antagonising that effect and utilise the body's own immune system to destroy cancer cells. ${ }^{93,94}$ The disruption of immune tolerance predisposes to immune-mediated dysfunction in endocrine glands and other organs. The relevant adverse events that can impact sodium homeostasis are hypophysitis-induced hypopituitarism, primary hypothyroidism and primary Al..$^{94,95}$

\section{Hypophysitis}

Hypophysitis occurs more commonly with CTLA4 inhibitors (ipilimumab) as compared with PD-1 or PD-L1 inhibitors, with a reported frequency of around $5.6 \%$ in a meta-analysis (95\% confidence interval [Cl], 3.9-8.1). ${ }^{96}$ In a retrospective study comprising 154 subjects with melanoma, central hypothyroidism was reported in all 17 cases of hypophysitis, while secondary or central Al was seen in $42 \%(7 / 17)$ of subjects. ${ }^{97}$ Cortisol exerts a negative feedback effect on the secretion of ADH and deficiency of cortisol causes non-osmotic secretion of $\mathrm{ADH}$, and that in turn causes water retention and dilutional hyponatraemia. ${ }^{29,98}$ Central diabetes insipidus secondary to immune checkpoint inhibition is unusual. There is only one reported case of avelumab-induced central diabetes insipidus secondary to infundibulo-hypophysitis, in a patient with Merkel cell carcinoma. Nocturia, polydipsia, and polyuria, which occurred 3 months after starting avelumab, reversed within 6 weeks of drug cessation..$^{99}$

\section{Primary hypothyroidism}

Primary hypothyroidism is more commonly reported with PD-1 inhibitors (nivolumab, pembrolizumab) and PD-L1 inhibitors (atezolizumab, avelumab, and durmalumab) as compared with CTLA4 inhibitors. ${ }^{100,101}$ The prevalence of hypothyroidism varies from 6-20\% in different series. ${ }^{101,102}$ Hyponatraemia can occur in the setting of hypothyroidism, the primary mechanism being augmented $\mathrm{ADH}$ release, resulting from a decrease in cardiac output-related stimulation of carotid baroreceptors. ${ }^{103}$

\section{Autoimmune adrenalitis}

Primary Al resulting from adrenalitis is an uncommon complication of immune checkpoint inhibitors. The predicted incidence of primary $\mathrm{Al}$ in a meta-analysis was $1.4 \%$ with ipilimumab (95\% Cl, 0.9-2.2), 2.0\% with nivolumab (95\% Cl, 0.9-4.3), and $0.8 \%$ with pembrolizumab monotherapy (95\% Cl, 0.3-2.0). The estimated incidence from combination therapy with two different immune checkpoint inhibitors was higher (5.2-7.6\%). ${ }^{96}$ In addition to the loss of inhibitory effect on ADH secretion resulting from hypocortisolism, deficiency of aldosterone further contributes to hyponatraemia by renal sodium loss and hypovolaemia-induced reflex increase in ADH secretion. ${ }^{104,105}$

\section{Monoclonal antibodies}

\section{Epidermal growth factor receptor}

Epidermal growth factor receptor (EGFR) is a transmembrane tyrosine kinase receptor that plays a critical role in the growth and survival of tumour cells. Cetuximab and panitumumab are mAbs against EGFR. ${ }^{106}$ According to the US Food and Drug Administration Adverse Event Reporting System (FAERS), there were 172 cases of acute kidney injury, 113 cases of hypokalaemia, 78 cases of hyponatraemia, 58 cases of hypomagnesaemia and 24 cases of hypertension with cetuximab. ${ }^{107}$

\section{Alemtuzumab}

Alemtuzumab is a mAb against CD52, a cell surface glycoprotein. SIADH was reported as an adverse effect of alemtuzumab in a case report. ${ }^{108}$

\section{Trastuzumab}

Trastuzumab is a mAb against human epidermal growth factor receptor 2 (HER2), approved for use in HER2-positive breast cancer and metastatic gastric cancer. Hyponatraemia has been reported in two cases with trastuzumab, but was likely caused by other concomitantly administered agents. ${ }^{109,110}$ Ado-trastuzamab emtansine is an antibody-drug conjugate comprising trastuzamab combined with the antimicrotubular maytansinoid agent, mertansine, and approved for the adjuvant treatment of HER2-positive early breast cancer. 
Though the initial clinical trials of this agent did not report hyponatraemia, there are rare reports of CSWS-induced hyponatraemia in patients of breast cancer with brain metastasis. ${ }^{11,112}$

\section{Other monoclonal antibodies}

Other mAbs, like the anti-CD20 antibodies (rituximab, crelizumab, obinutuzumab, veltuzumab, and ofatumumab) and the anti-vascular endothelial growth factor antibody (bevacizumab), have not been reported to alter sodium homeostasis.

\section{Other immunomodulators}

Immunomodulatory anticancer drugs of note include cytokines, such as interferon- $\alpha$ (IFN $\alpha$ ) and interleukin-2 (IL-2); thalidomide analogues and chimeric antigen receptor T-cell (CAR-T) therapy, and are discussed below.

\section{Cytokines}

Cytokines such as IFN $\alpha$ and IL-2 have largely been replaced as anticancer agents by more efficacious and better-tolerated alternatives. There are isolated case reports of SIADH induced by these agents, presumably via a stimulatory effect on ADH secretion. ${ }^{113,114}$ Their clinical relevance is minimal, due to their limited use in routine cancer treatment.

\section{Thalidomide analogues}

Thalidomide and its analogues lenalidomide and pomalidomide mediate their anticancer effects via antiangiogenic, antiproliferative and immunomodulatory activities. ${ }^{115} \mathrm{~A}$ retrospective analysis of severe hyponatraemia among hospitalised patients reported combination therapy of thalidomide and bortezomib as a cause of development of SIADH; however, bortezomib was the more likely aetiology. ${ }^{116} \mathrm{~A}$ combination of lenalidomide and rituximab produced hyponatraemia in $9 \%$ of 30 recipients with non-Hodgkin lymphoma. ${ }^{.17}$ In a phase II trial, the same combination produced hyponatraemia in $20 \%(9 / 45)$ of patients with non-Hodgkin lymphoma. ${ }^{118}$

\section{Chimeric antigen receptor T-cell therapies}

CAR-T therapy utilises the patient's own modified white blood cells to kill the cancer cells. Two CAR-T therapies are currently available axicabtagene ciloleucel and tisagenlecleucel. In a series of 78 patients receiving CAR-T therapy for diffuse large B-cell lymphoma, 51\% had hyponatraemia, and 15\% had sodium levels below $130 \mathrm{mmol} / \mathrm{L} . \%, 119$ The mechanism of hyponatraemia is presumed to be related to IL-6-induced ADH secretion in the background of cytokine release syndrome. ${ }^{120}$

\section{Tyrosine kinase inhibitors}

TKIs competitively inhibit cellular and receptor tyrosine kinases, which phosphorylate tyrosine residues in important signal-transducing proteins. These proteins are involved in regulating cellular proliferation, differentiation, migration, metabolism and antiapoptotic signalling, and are abnormally activated in cancer cells. 121,122 Hyponatraemia has been reported in a dose-dependent fashion with the commonly used TKIs imatinib, dasatinib, nilotinib, bosutinib and axitinib. ${ }^{45}$ This has also been also observed with sorafenib (up to $39 \%$ [9/23] of cases) and brivanib (9-11\%). ${ }^{123-125} \mathrm{~A}$ recent disproportionality analysis of the FAERS revealed hyponatraemia as an unexpected adverse event with gefitinib, erlotinib and afatinib. ${ }^{126}$ While it is known that SIADH causes the hyponatraemia associated with TKIs, the exact pathophysiology is unclear. It has been hypothesised that sorafenib stimulates the release of AVP by decreasing the renal papillary solute concentrations and increasing urinary osmolality. ${ }^{127}$ Proton pump inhibitors like omeprazole and rabeprazole are weak inhibitors of the cytochrome P450 3A4 enzyme. If used concomitantly with TKIS, they may increase plasma concentrations of TKI and precipitate SIADH. ${ }^{128,129}$

\section{Mammalian target of rapamycin inhibitors}

The phosphatidylinositol-3-kinase (PI3K)-Akt and the mTOR signalling pathways regulate vital cellular mechanisms controlling cell metabolism, growth, proliferation and survival. ${ }^{130} \mathrm{Abnormal}$ activation of this pathway is related to tumourigenesis. Temsirolimus and everolimus are mTOR inhibitors approved for use as anticancer agents. ${ }^{130}$ The clinical trials of several agents of these pathways have been hindered by severe toxicities such as hyperglycaemia, dyslipidaemia, bone marrow suppression and hepatotoxicity. ${ }^{131}$ Hyponatraemia has been seen in early clinical trials of temsirolimus and everolimus. ${ }^{132-137}$ The exact mechanism of hyponatraemia is unknown.

\section{Proteasome inhibitors}

Bortezomib, carfilzomib and ixazomib are the clinically relevant proteasome inhibitors that block the ubiquitin-proteasome system, which regulates the growth of healthy and tumour cells. Severe hyponatraemia has been reported in 2.6-25.9\% of patients receiving bortezomib. ${ }^{138}$ The mechanism underlying bortezomib-induced SIADH is not yet fully understood.

\section{Histone deacetylase inhibitors}

Vorinostat is an orally administered class I and II histone deacetylase (HDAC) inhibitor, which promotes cell cycle arrest and apoptosis in human haematopoietic cells and carcinoma cell lines. It is approved for use in patients with refractory cutaneous T-cell Iymphoma. ${ }^{139}$ Hyponatraemia is a rare, but crucial non-haematological, dose-limiting adverse effect of vorinostat. ${ }^{140}$ Hyponatraemia has also been observed with other HDAC inhibitors like romidepsin and belinostat. ${ }^{141-144}$ There is currently no literature available regarding the risk factors or mechanism of HDAC inhibitor-induced hyponatraemia.

\section{Hormonal therapies}

Hormonal agents target the growth of hormone-dependent tumours, like prostate and breast cancer, by regulating the production or action of sex hormones. Among these agents, gonadotropin-releasing hormone agonists commonly used in prostate cancer have been associated with severe hyponatraemia, where it occurs as part of the clinical spectrum of pituitary apoplexy. Pituitary apoplexy has been reported with the use of goserelin, leuprorelin, leuprolide and triptorelin, though theoretically, it can occur with any of the agents in this class. ${ }^{145}$ With rare exceptions, almost all cases of pituitary apoplexy have ensued in the presence of undiagnosed pituitary macroadenomas, the majority of which were gonadotropinomas. ${ }^{145,146}$ Symptoms commonly occur on the first day after the first dose, with rare presentations occurring as late as the ninth or tenth day following injection. ${ }^{145}$ Patients receiving these agents should be instructed and carefully monitored regarding symptoms of pituitary apoplexy and promptly undergo evaluation in cases of any suspicion. This is particularly important for the first 10-12 days following the first dose.

\section{Underlying mechanism}

While multiple factors could contribute to the increased risk of pituitary haemorrhage and apoplexy after gonadotropin-releasing hormone agonist administration, the exact mechanism is unknown. Guerra et al. proposed a dual mechanism involving an acute and a subacute process. The acute phase is characterised by an increase in metabolic rate and local vascular perfusion due to acute release of pituitary hormones causing ischaemic changes and necrosis in an abnormally vascularised adenoma. The subacute process is believed to be due to multiple factors such as intrinsic pituitary vascular abnormalities, large size of the adenoma, elevated intrasellar pressure with rapid growth of tumour, and ischaemic change and necrosis due to compromised blood supply. ${ }^{145}$ 
Table 3: Ancillary medications used with anticancer therapies commonly causing hyponatraemia and their suspected mechanisms

\begin{tabular}{|c|c|c|}
\hline Group name & Commonly used & Hyponatraemia \\
\hline Opioids & $\begin{array}{l}\text { Codeine } \\
\text { Morphine } \\
\text { Apomorphine } \\
\text { Hydrocodone }\end{array}$ & $\begin{array}{l}\text { - SIADH } \\
- \text { Opioids inhibit reuptake of serotonin, stimulation of } 5 \mathrm{HT}_{1} \text { and } 5 \mathrm{HT}_{2 \mathrm{C}} \text { receptors, increased release of ADH }{ }^{149} \\
- \text { Nausea and vomiting }{ }^{150} \\
\text { - Direct stimulation of thirst centre }\end{array}$ \\
\hline NSAIDS & $\begin{array}{l}\text { Ibuprofen } \\
\text { Indomethacin }\end{array}$ & Reduce renal prostaglandin production causing failure of usual inhibition of renal tubular ADH action ${ }^{152}$ \\
\hline TCAS & Amitryptiline & Inhibits serotonin reuptake, which increases $\mathrm{ADH}^{153}$ \\
\hline Anticonvulsants* & $\begin{array}{l}\text { Pregabalin } \\
\text { Gabapentin } \\
\text { Carbamazepine }\end{array}$ & SIADH ${ }^{154-156}$ \\
\hline PPIS & $\begin{array}{l}\text { Omeprazole } \\
\text { Esomeprazole } \\
\text { Pantoprazole }\end{array}$ & $\begin{array}{l}\text { Antidiuretic }{ }^{157} \\
\text { Potentiates ADH }{ }^{25} \\
\text { Possible renal salt wasting }{ }^{158}\end{array}$ \\
\hline Bisphosphonates & Zoledronic acid & Acute severe diarrhoea 159 \\
\hline
\end{tabular}

* Used for neuropathic pain management.

$5 H T_{1}=5$-hydroxytryptamine receptor 1; $5 H_{2} T_{2 C}=5$-hydroxytryptamine receptor 2C; $A D H=$ antidiuretic hormone; NSAIDS = non-steroidal anti-inflammatory drugs;

PPIS = proton pump inhibitors; SIADH = syndrome of inappropriate secretion of antidiuretic hormone; TCAS = tricyclic antidepressants.

Hyponatraemia occurs in $44 \%$ of pituitary apoplexy cases and has been postulated to correlate with hypocortisolism, hypothyroidism or SIADH, or a combination of these. ${ }^{147,148}$

\section{Ancillary treatments}

Several medications used in the supportive care setting may also cause hyponatraemia and require vigilance, especially when used alongside anticancer medications known to derange sodium homeostasis. ${ }^{149-159}$ Table 3 lists the ancillary drugs that have been found to cause hyponatraemia, along with their probable causal mechanisms. ${ }^{25,149-159}$

\section{Management}

The critical aspect of the management of hyponatraemia or hypernatraemia is to identify the aetiology. SIADH is the most common mechanism in the pathogenesis of hyponatraemia. The diagnosis of SIADH can be confirmed as per Schwartz and Bartter criteria, later updated by Ellison and Berl. ${ }^{160,161}$ The offending agent should be discontinued wherever possible. The therapeutic approach to hyponatraemia depends on its severity, rapidity of onset and symptomatology. Readers are referred to in-depth reviews by Grant et al. and Berardi et al. for detailed discussion on the management of hyponatraemia and SIADH. ${ }^{162,163}$

After administration of anticancer medicines, the onset of hyponatraemia can be within hours (e.g., with platinum-containing agents or alkylating drugs) or can be delayed by weeks (e.g., vincristine). ${ }^{42,54,78}$ Once the diagnosis of SIADH has been confirmed, discontinuation of the offending agent (if possible) should be strongly considered. Fluid restriction should be instituted in all cases of SIADH.

The decision to initiate intravenous hypertonic saline, vaptans or demeclocycline should be individualised. ${ }^{164}$ Severe acute hyponatraemia ( $<48$ hours) is a recognised complication of CYC and will warrant administration of hypertonic (3\%) saline to prevent seizures and other neurological complications. ${ }^{78,165}$ Chronic hyponatraemia ( $>48$ hours) should be corrected slowly in order to prevent osmotic demyelination syndrome, and the rate of correction should not exceed 6-8 mmol/day. ${ }^{166}$

Levothyroxine should be started 3-5 days after starting glucocorticoid replacement, to prevent precipitation of an acute adrenal crisis in cases of immune checkpoint inhibitor-induced hypopituitarism with involvement of both axes. Administration of physiological doses of glucocorticoid usually corrects hyponatraemia, but necessitates caution as there are reports of rapid correction of chronic hyponatraemia and occurrence of osmotic demyelination syndrome. ${ }^{167,168}$ Slow up-titration of glucocorticoid doses to physiological levels in those with long-standing hyponatraemia has been suggested by some authorities to prevent this. ${ }^{169}$ Rare cases of primary Al resulting from immune checkpoint inhibitors will require mineralocorticoid supplementation, in addition to glucocorticoids.

CSWS should be managed by volume and sodium repletion, and this can be performed using a combination of isotonic saline, hypertonic saline and mineralocorticoids. ${ }^{30}$ RSWS should be similarly treated with oral or intravenous saline supplementation. Fludrocortisone has been used with varying success. ${ }^{63,64}$ Hypovolaemic or hypervolaemic hyponatraemia should be managed accordingly.

Hypernatraemia is rare, and again identification of the cause is essential for appropriate management. Slow correction of water deficit with intravenous hypotonic fluid supplementation is the mainstay of therapy. ${ }^{170}$

\section{Conclusion}

Disordered sodium homeostasis is a significant adverse effect of anticancer therapy. Hyponatraemia occurs commonly after administration of conventional anticancer agents such as vinca alkaloids, platinum compounds and CYC and, less frequently, after targeted therapy. The most common underlying causal mechanism is the induction of SIADH. Other mechanisms include primary or secondary $\mathrm{Al}$, primary or secondary hypothyroidism, and increased renal sensitivity to ADH, CSWS and RSWS. Some anticancer agents have a specific temporal profile of the appearance of hyponatraemia, thus, care needs to be taken to anticipate and monitor for hyponatraemia according to the type of agent used. Certain ancillary medications, when used concomitantly, can worsen the risk of hyponatraemia, and need to be used with caution. Hypernatraemia is rare; however, it can theoretically occur in the background of drug-induced diabetes insipidus. Identification of the aetiology is central to appropriate management of an imbalance in sodium homeostasis. 
1. Livshits Z, Rao RB, Smith SW. An approach to chemotherapy-associated toxicity. Emerg Med Clin North Am. 2014;32:167-203.

2. Gizowski $\mathrm{C}$, Bourque $\mathrm{CW}$. The neural basis of homeostatic and anticipatory thirst. Nat Rev Nephrol. 2018:14:11-25.

3. Knepper MA, Kwon T-H, Nielsen S. Molecular physiology of water balance. N Eng/ J Med. 2015;372:1349-58.

4. Ball SG. Vasopressin and disorders of water balance: the physiology and pathophysiology of vasopressin. Ann Clin Biochem. 2007;44:417-31.

5. Patel S, Rauf A, Khan H, Abu-Izneid T. Renin-angiotensin-aldosterone (RAAS): The ubiquitous system for homeostasis and pathologies. Biomed Pharmacother. 2017;94:317-25

6. Fitzsimons JT. Angiotensin, thirst, and sodium appetite. Physiol Rev. 1998;78:583-686.

7. Stricker E, Sved A. Controls of vasopressin secretion and thirst: similarities and dissimilarities in signals. Physiol Behav. 2002;77:731-6.

8. Robben JH, Knoers NVAM, Deen PMT. Cell biological aspects of the vasopressin type-2 receptor and aquaporin 2 water channel in nephrogenic diabetes insipidus. Am J Physiol-Ren Physiol. 2006;291:F257-70.

9. Baylis PH. Osmoregulation and control of vasopressin secretion in healthy humans. Am J Physiol. 1987;253:R671-8.

10. Porzionato A, Macchi V, Stecco C, De Caro R. The carotid sinus nerve-structure, function, and clinical implications. Anat Rec. 2019;302:575-87

11. Fahim M. Cardiovascular sensory receptors and their regulatory mechanisms. Indian J Physiol Pharmacol. 2003;47:124-46.

12. Perlewitz A, Persson AE, Patzak A. The juxtaglomerular apparatus. Acta Physiol. 2012;205:6-8.

13. Malpas SC. Sympathetic nervous system overactivity and its role in the development of cardiovascular disease. Physiol Rev. 2010;90:513-57.

14. Rubattu S, Sciarretta S, Valenti V, et al. Natriuretic peptides: an update on bioactivity, potential therapeutic use, and implication in cardiovascular diseases. Am J Hypertens. 2008:21:733-41.

15. Goldsmith SR. Vasopressin as vasopressor. Am J Med. 1987:82:1213-9

16. Santos RAS, Oudit GY, Verano-Braga T, et al. The renin-angiotensin system: going beyond the classic paradigms. Am J Physiol Heart Circ Physiol. 2019;316:H958-70

17. Berghmans T, Paesmans M, Body J-J. A prospective study on hyponatraemia in medical cancer patients: epidemiology, aetiology and differential diagnosis. Support Care Cancer. 2000;8:192-7.

18. LiY, Chen $X$, Shen Z, et al. Electrolyte and acid-base disorders in cancer patients and its impact on clinical outcomes: evidence from a real-world study in China. Ren Fail. 2020;42:234-43.

19. Khan MI, Dellinger RP, Waguespack SG. Electrolyte disturbances in critically ill cancer patients: an endocrine perspective Intensive Care Med 2018:33:147-58.

20. Salahudeen AK, Doshi SM, Shah P. The frequency, cost, and clinical outcomes of hypernatraemia in patients hospitalized to a comprehensive cancer center. Support Care Cancer. 2013;21:1871-8

21. Ezoe $\mathrm{Y}$, Mizusawa J, Katayama $\mathrm{H}$, et al. An integrated analysis of hyponatremia in cancer patients receiving platinum-based or nonplatinum-based chemotherapy in clinica trials (JCOG1405-A). Oncotarget. 2017;9:6595-606.

22. Berardi R, Rinaldi S, Caramanti $M$, et al. Hyponatremia in cancer patients: Time for a new approach. Crit Rev Oncol Hematol. 2016;102:15-25.

23. Castillo JJ, Vincent M, Justice E. Diagnosis and management of hyponatremia in cancer patients. Oncologist. 2012;17:756-65.

24. Sørensen JB, Andersen MK, Hansen $\mathrm{HH}$. Syndrome of inappropriate secretion of antidiuretic hormone (SIADH) in malignant disease. I Intern Med. 1995;238:97-110.

25. Liamis G, Milionis HJ, Elisaf M. A review of drug-induced hypernatraemia. Am

6. Onitilo AA, Kio E, Doi SAR. Tumor-related hyponatremia. Clin Med Res. 2007;5:228-37.

27. Radulescu D, Pripon S, Bunea D, et al. Endocrine paraneoplastic syndromes in small cell lung carcinoma. Two case reports. JBUON. 2007:12:411-4.

28. Shimizu K, Nakano S, Nakano Y, et al. Ectopic atrial natriuretic peptide production in small cell lung cancer with the syndrome of inappropriate antidiuretic hormone secretion. Cancer. 1991;68:2284-8

29. Miljic D, Doknic M, Stojanovic M, et al. Impact of etiology, age and gender on onset and severity of hyponatremia in patients with hypopituitarism: retrospective analysis in a specialised endocrine unit Endocrine 2017:58:312-9.

30. Yee AH, Burns JD, Wijdicks EFM. Cerebral salt wasting: pathophysiology, diagnosis, and treatment. Neurosurg Clin

31. Girot H, Déhais M, Fraissinet F, et al. Atypica pseudohyponatremia. Clin Chem. 2018;64:414-5

32. Giri P, George J, Gupta AK, Gupta R. Pseudohyponatremia in multiple myeloma. J Assoc Physicians India. 2010;58:519-20.

33. Kumar B, Singh S, Skvortsova I, Kumar V. Promising targets in anti-cancer drug development: recent updates. Curr Med Chem. 2017;24:4729-52.

34. Wu P, Nielsen TE, Clausen MH. FDA-approved small-molecule kinase inhibitors. Trends Pharmacol Sci. 2015;36:422-39.

35. Berghmans T. Hyponatremia related to medical anticance treatment. Support Care Cancer. 1996:4:341-50.

36. Raftopoulos H. Diagnosis and management of hyponatremia in cancer patients. Support Care Cancer. 2007:15:1341-7.

37. Ravikumar TS, Grage TB. The syndrome of inappropriate ADH secretion secondary to vinblastine-bleomycin therapy. J Surg Oncol. 1983;24:242-5.

38. Janczar S, Zalewska-Szewczyk B, Mlynarski W. Severe hyponatremia in a single-center series of 84 homogenously treated children with acute lymphoblastic leukemia. J Pediatr
Hematol Oncol. 2017;39:e54-8.

3. Borker AS, Hutchins S, Grant R, et al. Syndrome of inappropriate secretion of anti-diuretic hormone in children with acute lymphoblastic leukemia. Blood.2006:108:4474.

40. Seetharam S, Thankamony P, Gopakumar KG, Krishna KM Higher incidence of syndrome of inappropriate antidiuretic hormone secretion during induction chemotherapy of acute lymphoblastic leukemia in indian children. Indian J Cancer. 2019;56:320-4

41. Spigel DR, Hainsworth JD, Lane $\mathrm{CM}$, et al. Phase II trial of vinflunine in relapsed small cell lung cancer. $J$ Thorac Oncol. 2010;5:874-8.

42. Hammond IW, Ferguson JA, Kwong K, et al. Hyponatremia and syndrome of inappropriate anti-diuretic hormone reported with the use of vincristine: an over-representation of Asians? Pharmacoepidemiol Drug Saf. 2002;11:229-34.

43. Moriyama B, Henning SA, Leung J, et al. Adverse interactions between antifungal azoles and vincristine: review and analysis of cases. Mycoses. 2012;55:290-7.

44. Nagappa M, Bhat RR, Sudeep K et al. Vincristine-induced acute life-threatening hyponatremia resulting in seizure and coma. Indian I Crit Care Med. 2009:13:167-8.

45. Liamis G, Filippatos TD, Elisaf MS. Electrolyte disorders associated with the use of anticancer drugs. Eur J Pharmacol. 2016;777:78-87

46. Suskind RM, Brusilow SW, Zehr J. Syndrome of inappropriate secretion of antidiuretic hormone produced by vincristine toxicity (with bioassay of ADH level). J Pediatr. 1972;81:90-2

4. Zavagli G, Ricci G, Tataranni G, et al. Life-threatening hyponatremia caused by vinblastine. Med Oncol Tumor Pharmacother. 1988:5:67-9.

48. Stuart MJ, Cuaso C, Miller M, Oski FA. Syndrome of recurrent increased secretion of antidiuretic hormone following multiple doses of vincristine. Blood. 1975:45:315-20.

49. Burdman JA. A note on the selective toxicity of vincristine sulfate on chick-embryo sensory ganglia in tissue culture J Natl Cancer inst 1966:37:331-5.

50. Rufener C, Nordmann J, Rouiller C. [Effect of vincristine on the rat posterior pituitary in vitro]. Neurochirurgie. 1972;18:137-41

1. Tomiwa K, Mikawa H, Hazama F, et al. Syndrome of inappropriate secretion of antidiuretic hormone caused by vincristine therapy: a case report of the neuropathology. J Neurol. 1983;229:267-72.

52. Garofeanu CG, Weir M, Rosas-Arellano MP, et al. Causes of reversible nephrogenic diabetes insipidus: a systematic review. Am J Kidney Dis. 2005;45:626-37.

53. Ali I, Wani WA, Saleem K, Haque A. Platinum compounds: a hope for future cancer chemotherapy. Anticancer Agents Med Chem. 2013;13:296-306.

54. Hatakeyama S, Shida T, Yamaguchi H. Risk factors for severe hyponatremia related to cisplatin: A retrospective case-contro study. Biol Pharm Bull. 2019;42:1891-7.

55. Arakawa Y, Tamura M, Sakuyama T, et al. Early measurement of urinary N-acetyl-p-glucosaminidase helps predict severe hyponatremia associated with cisplatin-containin chemotherapy. J Infect Chemother. 2015;21:502-6.

56. Shukuya T, Yamanaka T, Seto T, et al. Nedaplatin plus docetaxel versus cisplatin plus docetaxel for advanced or relapsed squamous cell carcinoma of the lung (WJOG5208L): a randomised, open-label, phase 3 trial. Lancet Oncol. 2015;16:1630-8.

57. Yamada Y, Higuchi K, Nishikawa K, et al. Phase III study comparing oxaliplatin plus S-1 with cisplatin plus S-1 in chemotherapy-naiive patients with advanced gastric cancer. Ann Oncol. 2015;26:141-8.

58. Matsumura $E$, Oshiro $Y$, Miyagi $R$, et al. [A case of renal salt wasting syndrome progressing to severe hyponatremia after gemcitabine-cisplatin chemotherapy]. Hinyokika Kiyo. 2012;58:425-9

59. Suzuki H, Hirashima T, Kobayashi M, et al. [Renal salt-wasting syndrome progressing to severe hyponatremi after chemotherapy--a case report]. Gan To Kagaku Ryoho. 2010;37:543-6.

60. Cao L, Joshi P, Sumoza D. Renal salt-wasting syndrome in a patient with cisplatin-induced hyponatremia: case report. Am J Clin Oncol. 2002;25:344-6.

61. Giaccone G, Donadio M, Ferrati P, et al. Disorders of serum electrolytes and renal function in patients treated with cis-platinum on an outpatient basis. Eur I Cancer Clin Oncol. 1985;21:433-7.

62. Gonzales-Vitale JC, Hayes DM, Cvitkovic E, Sternberg SS The renal pathology in clinical trials of cis-platinum (II) diamminedichloride Cancer 1977:39:1362-71.

63. Hutchison FN, Perez EA, Gandara DR, et al. Renal salt wasting in patients treated with cisplatin. Ann Intern Med. 1988;108:21-5.

64. Kurtzberg J, Dennis WW, Kinney TR. Cisplatinum-induced renal salt wasting. Med Pediatr Oncol. 1984;12:150-4.

65. Abid H, Siddiqui N, Gnanajothy R. Severe hyponatremia due to cisplatin-induced syndrome of inappropriate secretion of antidiuretic hormone. Cureus. 2019;11:e5458.

66. Tan AC, MarX GM. Cisplatin-induced syndrome of inappropriate antidiuretic hormone secretion (SIADH) with life-threatening hyponatraemia. BMJ Case Rep. 2018;2018:bcr2017222948.

67. Ohtaka M, Hattori Y, Kumano Y, et al. [Severe hyponatremia after cisplatin-based chemotherapy: two case reports. Hinyokika Kiyo. 2016;62:361-6.

68. Sawano T, Kawasaki H, Wajima N, et al. [A case of syndrome of inappropriate antidiuretic hormone secretion in a patient with esophageal carcinoma possibly induced by cisplatin in neoadjuvant chemotherapy]. Gan To Kagaku Ryoho. 2014:41:999-1003

69. Lee YK, Shin DM. Renal salt wasting in patients treated with high-dose cisplatin, etoposide, and mitomycin in patients with advanced non-small cell lung cancer. Korean I Intern Med. 1992;7:118-21.

70. Ready $\mathrm{NE}$, Pang $\mathrm{HH}$, Gu L, et al. Chemotherapy with or without

maintenance sunitinib for untreated extensive-stage small-cell lung cancer: A randomized, double-blind, placebo-controlled phase II study-CALGB 30504 (Alliance). J Clin Oncol. 2015;33:1660-5.

71. Khanna A. Acquired nephrogenic diabetes insipidus. Semin Nephrol. 2006;26:244-8.

72. Amlal H, Krane CM, Chen Q, Soleimani M. Early polyuria and urinary concentrating defect in potassium deprivation. Am J Physiol Renal Physiol. 2000;279:F655-63.

73. Clifton K, Barnett C, Martinez A, et al. Two case reports of severe hyponatremia following cyclophosphamide infusion in breast cancer patients. Breast J. 2018;24:691-2.

74. Bode U, Seif SM, Levine AS. Studies on the antidiuretic effect of cyclophosphamide: Vasopressin release and sodium excretion. Med Pediatr Oncol. 1980;8:295-303.

75. Bressler RB, Huston DP. Water intoxication following moderate-dose intravenous cyclophosphamide. Arch Intern Med. 1985;145:548-9.

76. Lee $\mathrm{Y}-\mathrm{C}$, Park J-S, Lee $\mathrm{CH}$, et al. Hyponatraemia induced by low-dose intravenous pulse cyclophosphamide. Nephrol Dial Transplant. 2010;25:1520-4.

77. Gilbar PJ, Richmond J, Wood J, Sullivan A. Syndrome of inappropriate antidiuretic hormone secretion induced by a single dose of oral cyclophosphamide. Ann Pharmacother. 2012;46:e23.

78. Bonella BM, Warley F. [Hyponatremia induced by high-dose cyclophosphamide therapy: a retrospective cohort study cyclophosphamide and hyponatremia]. Rev Fac Cienc Medicas Cordoba Argent. 2017;74:201-6.

79. Tang P, Zhang $Y$, Gao W, Geng C. Hyponatremia induced by low-dose cyclophosphamide in two patients with breast cancer. Breast J. 2014;20:442-3.

80. Kirch C, Gachot B, Germann N, et al. Recurrent ifosfamide-induced hyponatraemia. Eur J Cancer. 1997;33:2438-9.

81. Tsutsumi Y, Shiratori S, Nakata A, et al. Hyponatremia after administration of conditioning regimen in myelodysplastic syndrome with empty sella after glandula pituitaria surgery. Ann Hematol. 2007;86:843-4.

82. Shimizu T, Okamoto I, Tamura K, et al. Phase I clinical and pharmacokinetic study of the glucose-conjugated cytotoxic agent D-19575 (glufosfamide) in patients with solid tumors. Cancer Chemother Pharmacol. 2009;65:243-50.

83. Glezerman IG. Successful treatment of ifosfamide-induced hyponatremia with AVP receptor antagonist without interruption of hydration for prevention of hemorrhagic cystitis. Ann Oncol. 2009;20:1283-5.

84. Greenbaum-Lefkoe B, Rosenstock JG, Belasco JB. Syndrome of inappropriate antidiuretic hormone secretion. A complication of high-dose intravenous melphalan. Cancer. 1985;55:44-6.

85. Larose P, Ong H, du Souich P. The effect of cyclophosphamide on arginine vasopressin and the atrial natriuretic factor. Biochem Biophys Res Commun. 1987;143:140-4.

86. Campbell DM, Atkinson A, Gillis D, Sochett EB. Cyclophosphamide and water retention: $m$ mech
J Pediatr Endocrinol Metab. 2000;13:673-5.

87. Misharin AV, Resnenko AB, Fidelina OV, et al. Antidiuretic hormone-V2-receptor-aquaporin-2 system in rat kidneys during acute inflammation. Bull Exp Biol Med. 2004;138:452-6

88. Höcherl K, Schmidt C, Kurt B, Bucher M. Inhibition of NF-kappaB ameliorates sepsis-induced downregulation of aquaporin-2/N2 receptor expression and acute renal failure in vivo. Am J Physio Renal Physiol. 2010;298:F196-204.

89. Park SJ, Kim JH, Shin Jl. Insight on mechanism of hyponatraemia induced by low-dose intravenous pulse cyclophosphamide. Nephrol Dial Transplant. 2010;25:3453; author reply 3453-4.

0. MCBride WH, Hoon DB, Jung T, et al. Cyclophosphamide-induced alterations in human monocyte functions J LeukOC Biol 1987:42:659-66.

91. Finn $G$, Denning D. Transient nephrogenic diabetes insipidus following high-dose cyclophosphamide chemotherapy and autologous bone marrow transplantation. Cancer Treat Rep. 1987;71:220-1

92. Derman B, Jain M, MCAninch E, Gashti C. Bendamustine-induced nephrogenic diabetes insipidus. Clin Nephrol. 2017;87:47-50.

93. Sasidharan Nair V, Elkord E. Immune checkpoint inhibitors in cancer therapy: a focus on T-regulatory cells. Immunol Cell Biol. 2018;96:21-33

94. Seidel JA, Otsuka A, Kabashima K. Anti-PD-1 and anti-CTLA-4 therapies in cancer: Mechanisms of action, efficacy, and limitations. Front Oncol. 2018:8:86 
review and insights into underlying involved mechanisms. J Clin Endocrinol Metab. 2017:102:2770-80.

102. Osorio JC, Ni A, Chaft JE, et al. Antibody-mediated thyroid dysfunction during T-cell checkpoint blockade in patients with

103. Liamis G, Filippatos TD, Liontos A, Elisaf MS. Management of endocrine disease: hypothyroidism-associated hyponatremia: mechanisms, implications and treatment. Eur J Endocrinol. 2017:176:R15-20.

104. Ohara M, Cadnapaphornchai MA, Summer SN, et al. Effect of mineralocorticoid deficiency on ion and urea transporters and aquaporin water channels in the rat. Biochem Biophys Res Commun. 2002;299:285-90.

105. Arlt W, Allolio B. Adrenal insufficiency. Lancet Lond Engl. 2003:361:1881-93.

106. Martinelli E, De Palma R, Orditura M, et al. Anti-epidermal growth factor receptor monoclonal antibodies in cancer therapy. Clin Exp Immunol. 2009:158:1-9.

107. Jhaveri KD, Sakhiya $V$, Wanchoo $R$, et al. Renal effects of nove anticancer targeted therapies: a review of the Food and Drug Administration Adverse Event Reporting System. Kidney Int. 2016:90:706-7.

108. Kunz JS, Bannerji R. Alemtuzumab-induced syndrome of inappropriate anti-diuretic hormone. Leuk Lymphoma. 2005;46:635-7.

109. Yasuhara H, Imagawa A, Koike N, et al. [A case of renal salt-wasting syndrome during chemotherapy for advanced gastric cancer]. Gan To Kagaku Ryoho. 2015;42:225-7.

110. Turner N, Stewart J, Barnett F, White S. Syndrome of inappropriate anti-diuretic hormone secretion secondary to carboplatin after docetaxel-carboplatin-trastuzumab combination for early stage HER-2 positive breast cancer. Asia Pac J Clin Oncol. 2012;8:e9-11.

111. Wedam S, Fashoyin-Aje L, Gao X, et al. FDA approval summary: Ado-trastuzumab emtansine for the adjuvant treatment of HER2-positive early breast cancer. Clin Cancer Res. 2020;26:4180-5.

112. Kolarich AR, Reynolds BA, Heldermon CD. Ado-trastuzamab emtansine associated hyponatremia and intracranial hemorrhage. Acta Oncol. 2014;53:1434-6.

113. Björck $E$, Samuelsson J. Syndrome of inappropriate secretion of antidiuretic hormone (SIADH) after treatment with cyclophosphamide, $\alpha$-interferon and betamethasone in a patient with multiple myeloma. Eur J Haematol. 1996;56:323-5.

114. Mastorakos G, Weber JS, Magiakou MA, et al.

Hypothalamic-pituitary-adrenal axis activation and stimulation of systemic vasopressin secretion by recombinant interleukin- 6 in humans: potential implications for the syndrome of inappropriate vasopressin secretion. J Clin Endocrinol Metab. 1994:79:934-9.

115. Zhu YX, Kortuem KM, Stewart AK. Molecular mechanism of action of immune-modulatory drugs thalidomide, lenalidomide and pomalidomide in multiple myeloma. Leuk Lymphoma. 2013;54:683-7.

116. Hoorn EJ, Lindemans J, Zietse R. Development of severe hyponatraemia in hospitalized patients: treatment-related risk factors and inadequate management. Nephrol Dial Transplant. 2006;21:70-6

117. Tuscano JM, Dutia M, Chee K, et al. Lenalidomide plus rituximab can produce durable clinical responses in patients with relapsed or refractory, indolent non-Hodgkin lymphoma. Br J Haematol. 2014;165:375-81.

118. Wang M, Fowler N, Wagner-Bartak N, et al. Oral lenalidomide with rituximab in relapsed or refractory diffuse large cell, follicular and transformed lymphoma: a phase II clinical trial. Leukemia. 2013;27:1902-9.

119. Gupta S, Seethapathy H, Strohbehn IA, et al. Acute kidney injury and electrolyte abnormalities after chimeric antigen receptor T-cell (CAR-T) therapy for diffuse large B-cell lymphoma. T-cell (CAR-T) therapy for diffuse

120. Dixon BN, Daley RJ, Buie LW, et al. Correlation of IL-6 secretion and hyponatremia with the use of $\mathrm{CD} 19+$ chimeric antigen receptor T-cells. Clin Nephrol. 2020;93:42-6.

121. Jhaveri KD, Wanchoo R, Sakhiya V, et al. Adverse renal effects of novel molecular oncologic targeted therapies: A narrative review. Kidney Int Rep. 2017;2:108-23.

122. Biswas B, Ghadyal patil N, Krishna M, Deshmukh J. A review on adverse event profiles of epidermal growth factor receptor-tyrosine kinase inhibitors in nonsmall cell lung cancer patients. Indian J Cancer. 2017;54(Suppl.):S55-64.
123. Lalami Y, Garcia C, Flamen P, et al. Phase II trial evaluating the efficacy of sorafenib (BAY 43-9006) and correlating early fluorodeoxyglucose positron emission tomography-CT response to outcome in patients with recurrent tomography-CT response to outcome in patients with recurrent with recurrent and/or metastatic head and neck cancer. with recurrent and/or metastatic
Head Neck. 2016;38:347-54.

124. Llovet JM, Decaens T, Raoul J-L, et al. Brivanib in patients with advanced hepatocellular carcinoma who were intolerant to sorafenib or for whom sorafenib failed: results from the randomized phase III BRISK-PS study. J Clin Oncol. 2013;31:3509-16

125. Johnson PJ, Qin S, Park J-W, et al. Brivanib versus sorafenib as first-line therapy in patients with unresectable, advanced hepatocellular carcinoma: results from the randomized phase III BRISK-FL study. J Clin Oncol. 2013;31:3517-24.

126. Huang J, Meng L, Yang B, et al. Safety profile of epidermal growth factor receptor tyrosine kinase inhibitors: a disproportionality analysis of FDA adverse event reporting system. Sci Rep. 2020:10:4803.

127. Khaja M, Torchon F, Millerman K. A rare case of sorafenib-induced severe hyponatremia. SAGE Open Med Case Rep. 2019;7:2050313X1984604

128. Liapis K, Apostolidis J, Charitaki E, et al. Syndrome of inappropriate secretion of antidiuretic hormone associated with imatinib. Ann Pharmacother. 2008;42:1882-6.

129. Hill J, Shields J, Passero V. Tyrosine kinase inhibitor-associated syndrome of inappropriate secretion of anti-diuretic hormone J Oncol Pharm Pract. 2016;22:729-32.

30. Laplante M, Sabatini DM. mTOR signaling at a glance. J Cell SCi. 2009;122:3589-94.

131. Tian T, Li X, Zhang J. mTOR signaling in cancer and $M T O R$ inhibitors in solid tumor targeting therapy. Int J Mol Sci. 2019:20:755.

132. Kaplan B, Qazi Y, Wellen JR. Strategies for the management of adverse events associated with mTOR inhibitors. Transplant Rev (Orlando). 2014:28:126-33.

133. Guo J, Huang Y, Zhang $X$, et al. Safety and efficacy of everolimus in Chinese patients with metastatic renal cell carcinoma resistant to vascular endothelial growth factor receptor-tyrosine kinase inhibitor therapy: an open-labe phase 1b study. BMC Cancer. 2013;13:136.

34. Javle MM, Shroff RT, Xiong H, et al. Inhibition of the mammalian target of rapamycin (mTOR) in advanced pancreatic cancer. results of two phase II studies. BMC Cancer. 2010;10:368.

135. Yeo W, Chan SL, Mo FK, et al. Phase I/II study of temsirolimus for patients with unresectable hepatocellular carcinoma (HCC) - a correlative study to explore potential biomarkers for response. BMC Cancer. 2015:15:395.

136. Sánchez-Fructuoso Al, Santín Cantero JM, Pérez Flores I, et al. Changes in magnesium and potassium homeostasis after conversion from a calcineurin inhibitor regimen to an MTOR inhibitor-based regimen. Transplant Proc 2010:42:3047-9.

137. Zhu AX, Abrams TA, Miksad R, et al. Phase $1 / 2$ study of everolimus in advanced hepatocellular carcinoma. Cancer 2011;117:5094-102

138. LV C-L, Li J. Bortezomib as a probable cause of the syndrome of inappropriate antidiuretic hormone secretion: A case report and review of the literature. Mol Clin Oncol. 2017;7:667-72.

39. Schelman WR, Traynor AM, Holen KD, et al. A phase I study of vorinostat in combination with bortezomib in patients with advanced malignancies. Invest New Drugs. 2013;31:1539-46.

140. Holkova B, Kmieciak M, Bose P, et al. Phase 1 trial of carfilzomib (PR-171) in combination with vorinostat (SAHA) in patients with relapsed or refractory B-cell lymphomas. Leuk Lymphoma. 2016;57:635-43.

141. Amengual JE, Lichtenstein R, Lue J, et al. A phase 1 study of romidepsin and pralatrexate reveals marked activity in relapsed and refractory T-cell lymphoma. Blood. 2018:131:397-407.

142. Piekarz RL, Frye R, Prince HM, et al. Phase 2 trial of romidepsin in patients with peripheral T-cell lymphoma. Blood. 2011;117:5827-34

43. Gimsing P, Hansen M, Knudsen LM, et al. A phase I clinical trial of the histone deacetylase inhibitor belinostat in patients with advanced hematological neoplasia. Eur I Haematol. 2008;:81:170-6.

144. Ramalingam SS, Belani CP, Ruel C, et al. Phase II study of belinostat (PXD101), a histone deacetylase inhibitor, for second line therapy of advanced malignant pleural mesothelioma. J Thorac Oncol. 2009;4:97-101.
145. Guerra Y, Lacuesta E, Marquez F, et al. Apoplexy in non functioning pituitary adenoma after one dose of leuprolide as treatment for prostate cancer. Pituitary. 2010;13:54-9.

146. Huang T-Y, Lin J-P, Lieu A-S, et al. Pituitary apoplexy induced by gonadotropin-releasing hormone agonists for treating prostate cancer-report of first Asian case World I Surg Oncol. 2013;11:254.

147. Engel G, Huston M, Oshima S, et al. Pituitary apoplexy afte leuprolide injection for ovum donation. J Adolesc Health. 2003;32:89-93

148. Randeva HS, Schoebel J, Byrne J, et al. Classical pituitary apoplexy: clinical features, management and outcome. Clin Endocrinol (OXf). 1999;51:181-8.

149. Karahan S, Karagoz H, Erden A, et al. Codeine-induced syndrome of inappropriate antidiuretic hormone: case report. Balk Med J. 2014;33:107-9.

150. Day L, Kleinschmidt K, Forrester MB, Feng S-Y. Comparison of unintentional exposures to codeine and hydrocodone reported to Texas poison centers. J Emerg Med. 2016;50:744-52.

151. Nagatomo I, Katafuchi T, Koizumi K. Effects of the opiates on the paraventricular nucleus in genetically polydipsic mice. Brain Res. 1992;598:23-32.

152. Kramer HJ, Glänzer K, Düsing R. Role of prostaglandins in the regulation of renal water excretion. Kidney Int. 1981;19:851-9.

153. Degner D, Grohmann R, Kropp S, et al. Severe adverse drug reactions of antidepressants: results of the German multicenter drug surveillance program AMSP. Pharmacopsychiatry. 2004;37(Suppl. 1):S39-45.

154. Shepshelovich D, Schechter A, Calvarysky B, et al. Medication-induced SIADH: distribution and characterization according to medication class: Medication-induced SIADH characterization. Br J Clin Pharmacol. 2017;83:1801-7.

155. Wilton LV, Shakir S. A postmarketing surveillance study of gabapentin as add-on therapy for 3,100 patients in England. Epilepsia 2002:43:983-92.

156. Kaeley N, Kabi A, Bhatia R, Mohanty A. Carbamazepine-induced hyponatremia - A wakeup call. J Fam Med Prim Care 2019;8:1786-8.

157. Buon M, Gaillard C, Martin J, et al. Risk of proton pump inhibitor-induced mild hyponatremia in older adults. J Am Geriatr Soc. 2013;61:2052-4.

158. Ferreira F, Mateus S, Santos AR, et al. Pantoprazole-related symptomatic hyponatremia. Eur I Case Rep Intern Med 2016;3:000341

159. Shafi Kuchay M. Acute severe diarrhoea and hyponatremia after zoledronic acid infusion: an acute phase reaction. Clin Cases Miner Bone Metab. 2017;14:101.

160. Bartter FC, Schwartz WB. The syndrome of inappropriate secretion of antidiuretic hormone. Am J Med. 1967;42:790-806.

161. Ellison DH, Berl T. The syndrome of inappropriate antidiuresis. N Eng/ J Med. 2007:356:2064-72.

162. Grant P, Ayuk J, Bouloux P-M, et al. The diagnosis and management of inpatient hyponatraemia and SIADH. Eur J Clin Invest. 2015;45:888-94.

163. Berardi R, Antonuzzo A, Blasi L, et al. Practical issues for the management of hyponatremia in oncology. Endocrine. 2018;61:158-64

164. Gross P. Clinical management of SIADH. Ther Adv Endocrinol Metab. 2012;3:61-73.

165. Elazzazy S, Mohamed AE, Gulied A. Cyclophosphamide-induced symptomatic hyponatremia, a rare but severe side effect: a case report. Onco Targets Ther. 2014;7:1641-5.

166. Sterns RH. Treatment of severe hyponatremia. Clin J Am SOC Nephrol. 2018;13:641-9.

167. Lasheen I, Doi SAR, Al-Shoumer KAS. Glucocorticoid replacement in panhypopituitarism complicated by myelinolysis. Med Princ Pract. 2005:14:115-7.

168. Lee W-C, Cheng Y-F, Chen J-B. Treating hyponatremia in an empty sella syndrome patient complicated with possible myelinolysis. Chang Gung Med J. 2002;25:838-43.

169. Yoshioka K, Minami M, Fujimoto S, et al. Incremental increases in glucocorticoid doses may reduce the risk of osmotic demyelination syndrome in a patient with hyponatremia due to central adrenal insufficiency. Intern Med Tokyo Jph. 2012;51:1069-72

170. Muhsin SA, Mount DB. Diagnosis and treatment of hypernatraemia. Best Pract Res Clin Endocrinol Metab. 2016;30:189-203. 